Fighting back
Therapeutic vaccine
shows promise
against HIV
0650

\title{
Flight records reveal full extent of Agent Orange contamination
}

\section{Declan Butler}

A fresh study of long-forgotten flight records of US military aircraft that sprayed Agent Orange over Vietnam has shed unexpected light on one of the darkest episodes of that conflict.

The study, published on page 681 of this issue, revises previous estimates of the quantity of the herbicide sprayed during the Vietnam War sharply upwards. Together with the earlier use of other herbicides known as Agent Purple and Agent Pink - it finds that the total amount of dioxin contaminant sprayed in the war was up to four times as great as was previously estimated.

And in a report due to be released on 17 April, the US Institute of Medicine declares that the new work shows that it is feasible to perform large-scale epidemiological studies of the links between the herbicide spraying and the health of the Vietnamese population and US veterans. The institute calls on the US government to support such studies.

The new analysis, performed by a group led by Jeanne Mager Stellman at Columbia University in New York, provides the most detailed and sophisticated computerized maps ever produced of herbicide spraying in Vietnam. For the first time, the authors say, it is possible to calculate an exposure index for individuals and populations that is accurate enough for the epidemiological research that is needed for firm links with health data.

Stellman's team calculated the index by compiling a computer database that overlays staggering amounts of various data, much of it newly unearthed, onto geographical coordinates. The data include flight-path information, the amount and type of agents delivered (including releases caused by leaks, crashes and dumps), troop locations and movements, land features and soil type, and the location of Vietnamese populations.

"I just think, 'Wow', if only this had been around earlier," says Alistair Hay, an environmental toxicologist at the University of Leeds, UK. "It fills in the gaps, giving an accurate and comprehensive picture of where spraying took place."

Like a widely cited 1974 National Academy of Sciences study on Agent Orange, the

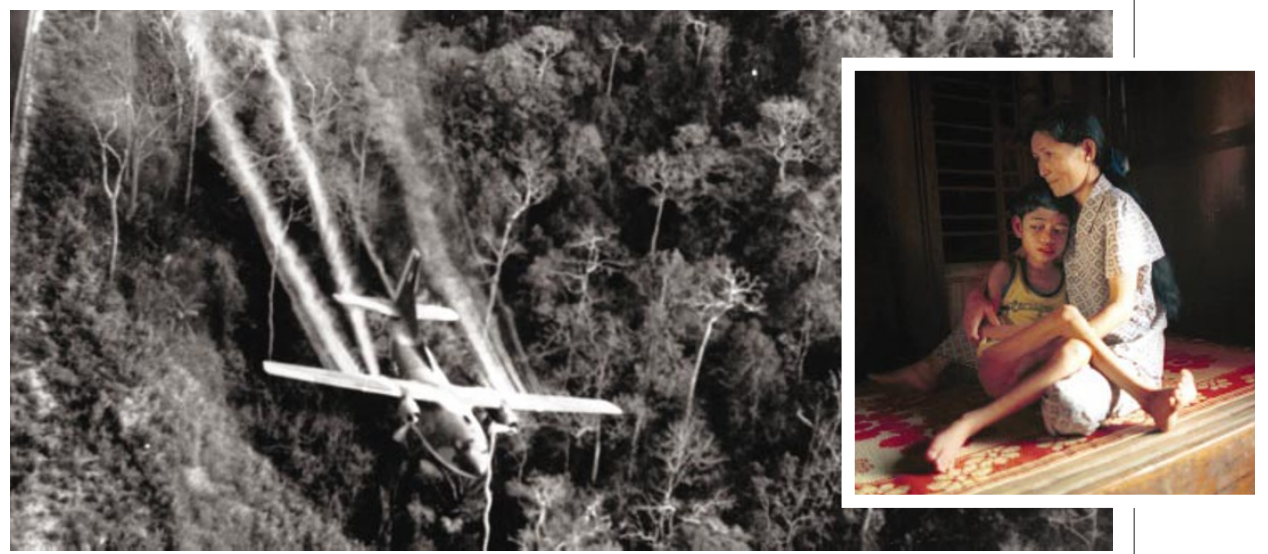

Up to 4 million Vietnamese may have been affected by American wartime defoliant spraying.

researchers relied heavily on HERBS, an electronic record compiled by the US military, which includes data on flight paths, herbicide agents and volumes used, and other information on 10,000 spraying missions. But when digging out and cleaning up these data, the team stumbled on valuable archive data that had been overlooked, and discovered a connection that allowed them to extract far more information from existing records.

A major shortcoming of earlier analyses using HERBS was that its spraying data were treated chronologically, leading to mission flight paths criss-crossing the country but without showing patterns of which areas were sprayed over time. The new study's breakthough came when Stellman, browsing army archives, found another source of information: the daily logs filed by pilots after missions. "It was a sort of 'eureka moment' when I realized that there were 'project' numbers on each of these reports, and that those numbers vaguely resembled a couple of columns that we have never put together before or used," she says. "I just thought, 'Oh my God, look at this!'.”

These columns of numbers included a column called 'missionnum', which, when linked with data in the 'military region' column, matched up with project numbers kept in the pilots' logs. The logs contained exactly what HERBS lacked: details of the missions' targets. The link enabled the team to draw the first maps of spraying patterns in Vietnam that show precise localized target zones, and how much herbicide was sprayed on them and when.

It is possible to tell from the maps, for example, whether individual soldiers or populations were likely to be present in a particular zone on the day of spraying and exposed directly, or whether they arrived later and were exposed indirectly.

The findings are set to provoke a vigorous reaction both from US veterans' groups some of which are still seeking compensation for exposure to Agent Orange - and the Vietnamese government. Using census data for 20,000 Vietnam hamlets for the first time, the study shows that at least 3,000 of them were sprayed directly, affecting between 2 million and 4 million people. The researchers also plan to publish maps of spraying in relation to US troop positions.

The model used in the study is "a valid means for assessing wartime herbicide exposure in Vietnam veterans", says the Institute of Medicine report, written by a committee chaired by David Hoel, an epidemiologist at the Medical University of South Carolina in Charleston. It commends the team for its "dogged pursuit of historical records" and recommends that the Department of Veterans Affairs, which funded the study, work with other government agencies to support new epidemiological studies of veterans' health. 